Portland State University

PDXScholar

Fall 2021

\title{
Plastic-Eating Microbes: a New Potential Solution to Waste Mitigation?
}

Megan Forbes

Portland State University

Follow this and additional works at: https://pdxscholar.library.pdx.edu/honorstheses

Part of the Integrative Biology Commons

Let us know how access to this document benefits you.

Recommended Citation

Forbes, Megan, "Plastic-Eating Microbes: a New Potential Solution to Waste Mitigation?" (2021).

University Honors Theses. Paper 1152.

https://doi.org/10.15760/honors.1181

This Thesis is brought to you for free and open access. It has been accepted for inclusion in University Honors Theses by an authorized administrator of PDXScholar. Please contact us if we can make this document more accessible: pdxscholar@pdx.edu. 
Plastic-Eating Microbes: A New Potential Solution to Waste Mitigation?

by

\section{Megan Forbes}

An undergraduate honors thesis submitted in partial fulfillment of the requirements for the degree of

Bachelor of Science

in

University Honors

and

Biology

Thesis Advisor

Dr. Annie Lindgren

Portland State University 


\section{Abstract:}

Plastic waste is problematic for marine and terrestrial ecosystems due to the mass production of polyethylene terephthalate (PET) single use plastics (Carr et al., 2020; Doyle, et al., 2011). What is unclear is a well-thought-out solution to solve pollution problems that will not further damage the environment. Throughout this literature review, I will investigate the role microbes play in plastic degradation, and if plastic eating microbes are an effective solution to the plastic pollution problem. Polyethylene terephthalate (PET) is the chemical name for polyester. It is a clear, strong, and lightweight plastic that is typically used for food and beverage packaging, and other single-use purposes. The most well understood organism identified to be capable of plastic degradation is the heterotrophic bacteria Ideonella sakaiensis (Flashman, 2018). I. sakaiensis can ultimately break down polyethylene plastics with the enzymes PETase and MHETase, making them potentially effective at mitigating the plastic waste crisis. On the scale necessary to solve the global problem of plastic pollution, relying primarily on plastic-eating microbes is currently unrealistic. Currently, research is branching in several different directions: 1) how plastic affects marine and terrestrial organisms, 2) how plastic enters the human food chain and causes health problems, and 3) how microbes degrade plastic. Future research could likely focus on expanding small-scale experiments on heterotrophic microbes to larger scale processing in an industrial waste facility (Carr et al., 2020), or working to combine the high PETase hydrolytic activity with thermostable PHEs to incorporate higher thermostability to PETase (Taniguchi et al., 2019).

\section{Introduction:}


It is well known that plastic waste is problematic for both marine and terrestrial ecosystems, with the cause being attributed to the mass production of polyethylene terephthalate (PET) plastics for food containers, films, fibers, and bottles (Carr et al., 2020; Doyle, et al., 2011). What is unclear is a well-thought-out solution to solve pollution problems that will not further damage the environment. With this in mind, my thesis will explore the potential to use plastic-eating microorganisms for plastic degradation rather than conventional methods, such as burning and landfilling which release harmful byproducts, and recycling, which is often limited. Specifically, I will investigate two primary questions: 1) What role can microbes play in plastic degradation? and 2) Are plastic eating microbes an effective solution to the plastic pollution problem? Through a literature review, I will further investigate how microorganisms use plastic as an energy source to determine if they are a viable solution to shield our ecosystems from the rise of plastic pollution.

\section{Background Information:}

Microbes are microscopic organisms that belong to two Domains of life: Archaea and Eubacteria. Microbes include primary producers that convert light and other compounds to energy, heterotrophs/decomposers who obtain energy from external sources, and are found everywhere. Microbes have a substantial influence on people's lives; they clean up the environment, make soil fertile, influence food technology, and produce nutrients that our bodies need (Postgate, 2003). Most of the time, we coexist with microbes without even realizing it. While some microbes protect us from other harmful organisms, others can be responsible for outbreaks of disease, food spoilage, deterioration or decomposition, etc. (Postgate, 2003). For this particular project, I am focusing on the environmental and deterioration capabilities of 
heterotrophic microbes from the Domain Eubacteria, specifically Ideonella sakaiensis and those similar to it who have been hypothesized to be able to directly break down plastic compounds.

Polyethylene terephthalate (PET) is the chemical name for polyester. It is a clear, strong, and lightweight plastic that is typically used for food and beverage packaging, and other single-use purposes such as mouthwash, shampoo, hand soap, cleaners, and even tennis balls. PET was first synthesized in North America during the 1940s by Dupont chemists who were searching for new synthetic fibers (PETRA, 2015). To this day, over $50 \%$ of the world's synthetic fiber is made from PET, referred to as "polyester" when used for fibers or fabrics, and PET or PET resin when used for containers. See Table 1 for a breakdown down the most common applications for PET plastic and the amount produced annually.

Table 1: a compilation of the different categories of plastic and the products that fit into them, measured by millions of tons produced annually (Cornwall, 2021).

\begin{tabular}{|c|c|c|c|c|c|c|}
\hline Polyethylene & Polypropylene & $\begin{array}{l}\text { Polyvinyl } \\
\text { Chloride }\end{array}$ & $\begin{array}{c}\text { Polyethylene } \\
\text { Terephthalate } \\
\text { (PET) }\end{array}$ & Polystyrene & Polyurethane & Other \\
\hline $\begin{array}{l}\text { Sandwich } \\
\text { bags } \\
\text { Trays and } \\
\text { containers } \\
\text { Food } \\
\text { packaging } \\
\text { film }\end{array}$ & $\begin{array}{l}\text { Food } \\
\text { packaging } \\
\text { Snack } \\
\text { wrappers } \\
\text { Microwavable } \\
\text { containers } \\
\text { Automotive } \\
\text { parts }\end{array}$ & $\begin{array}{l}\text { Window } \\
\text { frames } \\
\text { Cable } \\
\text { insulation } \\
\text { Garden } \\
\text { hoses } \\
\text { Inflatable } \\
\text { pools }\end{array}$ & $\begin{array}{l}\text { Water bottles } \\
\text { Soft drink } \\
\text { bottles } \\
\text { Cleaner } \\
\text { bottles }\end{array}$ & 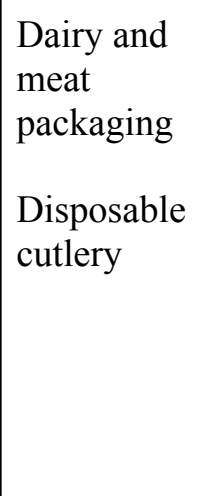 & $\begin{array}{l}\begin{array}{l}\text { Building } \\
\text { insulation }\end{array} \\
\text { Kitchen } \\
\text { sponges } \\
\text { Pillows and } \\
\text { mattresses }\end{array}$ & 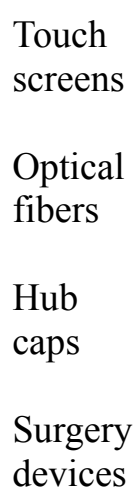 \\
\hline $116 \mathrm{Mt}$ & $68 \mathrm{Mt}$ & $38 \mathrm{Mt}$ & $33 \mathrm{Mt}$ & $25 \mathrm{Mt}$ & $27 \mathrm{Mt}$ & $75 \mathrm{Mt}$ \\
\hline
\end{tabular}


Plastic products are durable, have a low production cost, and have vast applications in several sectors, which makes them high in demand from a convenience and cost perspective (Sharuddin et al., 2016). Thirty to $40 \%$ of plastics are produced across the world for various packaging purposes and other single-use products, all of which contributes to the rising plastic garbage at a rate of $12 \%$ per year (Jaiswal, et al., 2020). Further complicating the waste problem is that plastics are made to be robust and the physical factors of the plastic including: surface area, functional chemical groups that are used to make the plastics, molecular weight, hydrophilicity/hydrophobicity, melting temperature, and chemical structure, among others significantly impact and limit deterioration rates (Jaiswal, et al., 2020). These properties in tandem with the increased demand has led to a continued build up and persistence of plastics in marine and terrestrial environments over the years.

PET waste accumulates in both marine and terrestrial environments, which leads to harm and/or death of inhabitants. Plastic is responsible for the death of approximately one million sea birds, and 100,000 marine mammals and turtles per year, due largely to strangulation and suffocation (Carr et al., 2020; Isangedighi et al., 2021). Furthering the pervasiveness of plastic waste and harm is the partial breakdown of discarded plastics and treatment of synthetic fibers that results in widespread dispersal of microplastics and microfilms, termed "microplastics." Microplastics are small plastic pieces that are no more than five millimeters long, and can originate from a number of sources including: fragmentation of larger macro-plastic debris, pre-production pellets spilled during transport, outflow of wastewater containing microbeads from cosmetics or fibers, and road-run-off containing fragments of vehicle tires and paint (Nelms et al., 2019). These microplastic shards can be ingested directly through accidental consumption, or they may be ingested indirectly through trophic transfer where predators consume prey that 
have been contaminated with microplastics (Nelms et al., 2019). In marine environments, organisms ingesting microplastics is a relatively new subject of interest and has recently become a large concern (Markie et al., 2019). A recent study assessed the presence of microplastics in the digestive tracts of 43 cetaceans of eight different species, and seven pinnipeds of two different species (Nelms et al., 2019). The researchers were seeking to understand the general abundance of microplastics ingested by individuals, what polymers were involved, and if they are egested (discharged as undigested food) or are retained in the digestive tract (Nelms et al., 2019). Through an assessment of the entire digestive system of each individual, the team detected microplastics in all 50 mammals examined in the study, however the average amount of microplastics detected was low (mean 5.5), which implies that the microplastic particles of interest are transitory, able to be passed by the animal and are not considered permanent (Nelms et al., 2019). This does not mean that all microplastic particles consumed are transitory, however, because the researchers discovered that the mammals' stomachs contained more microplastics than the intestines which would indicate at least some retention in their systems (Nelms et al., 2019). After analyzing their data, the researchers discovered a potential relationship between the cause of death category of the mammals and their microplastic abundance. Animals that died due to infectious diseases contained a slightly higher amount of particles than those that died of trauma or other causes, however it is worth noting that this is a casual relationship until more research is conducted (Nelms et al., 2019). This study should be eye opening, because in terms of ocean pollution whales, dolphins, and seals are considered important indicators of marine ecosystem health because most of them have a long life span, high trophic level feeding status, and are susceptible to bioaccumulation and biomagnification of chemical contaminants (Nelms et al., 2019). Such results should leave us wondering what remediations to mitigate our waste 
crisis are available, and where new groundbreaking work can be done if we are to save such organisms from the pain and suffering of humanity's solution to cheap containers and clothing fibers.

In terrestrial environments, soils may pose as a sink for plastics and microplastics because they can readily leach from soil into groundwater and contaminate other water sources, which can be problematic for the terrestrial organisms and ecosystems (Carr et al., 2020). For example, one team of researchers conducted a study on stinging wasps to examine the ingestion and toxicity of polyamide (nylon) particles that fall into different size categories (Lahive et al., 2019). The researchers used the stinging wasp Euodynerus crypticus to determine how particle size affected their survival and reproduction when exposed to nylon particles from the two size ranges $13-18$ and 90-150 micrometers, and concentrations of $20,50,90$, and $120 \mathrm{~g} / \mathrm{kg}$, which is $2-12 \% \mathrm{w} / \mathrm{w}$ (Lahive et al., 2019). In addition to nylon, polyvinyl chloride (PVC) particles at 106-150 micrometers in size and $90 \mathrm{~g} / \mathrm{kg}$ concentration were tested as well (Lahive et al., 2019). It was determined that neither polymer types at any size range affected the ability for E. crypticus to survive, however reproduction ability was significantly reduced on a scale controlled by dosage and/or concentration (Lahive et al., 2019). Reproduction was most greatly affected by nylon particles at high exposure concentrations, $90 \mathrm{~g} / \mathrm{kg}$ and higher (Lahive et al., 2019). Smaller size ranges (13-18 micrometers) had a larger effect than larger size ranges of particles (greater than 63 micrometers), which could potentially be linked to E. crypticus ingesting a greater amount of those smaller particles, however more research is needed to explore this relationship (Lahive et al., 2019). This study demonstrates the possibility of toxic effects from plastics and microplastics in-dwelling organisms at high exposure concentrations, which poses a threat to the terrestrial environment. A different study was conducted on the earthworm Lumbricus terrestris 
that exposed them to polyethylene microplastics that were 150 micrometers in size or smaller in concentrations of 7, 28, 45, and 60\% dry weight (Lwanga et al., 2016).

Microplastics not only contaminate marine and terrestrial ecosystems and organisms, they also enter human food chains. This contamination can lead to adverse health effects including immune disorders, congenital diabetes, and cancer in both animals and humans (Llorca and Farré, 2021). Plankton, fish, and humans ingest carcinogens from plastic waste through the food chain, either directly from the water or soil, or indirectly from their food where these plastics are "bio accumulated" in the food web, eventually concentrating in animals that humans consume (Jaiswal et al., 2020). In addition to direct consumption in food, animals, including humans, are exposed to micro and nanoplastics (MNPLs) through inhalation, accidental ingestion, and less significantly through skin contact (Llorca and Farré, 2021). For reference, nanoplastics are particles less than 100 nanometers in size, which is 0.0001 millimeters or smaller - these are of concern because they are small enough to likely pass through biological membranes and affect functioning cells. MNLPs have complex additives such as plasticisers (increase plastic softness and flexibility), flame retardants, fillers, UV stabilizers, coating finishers, colorants, and metals to name a few (Llorca and Farré, 2021). While the plastic shards on their own can cause damage, it is the complex additives that significantly do harm when they are broken down and released in the body where toxic effects are demonstrated. Additives such as polybrominated diphenyl ethers (PBDEs), bisphenol A, and some phthalates have been studied the most in the last ten years, and have been determined by researchers to be linked to carcinogenicity, neurotoxicity, obesity, and endocrine disruption (Llorca and Farré, 2021). These consequences, along with those mentioned regarding marine digestion of plastic, are monumental issues that need to be addressed. We should ask ourselves, where we go from here and who is responsible for how we rectify these 
serious consequences because if remediation does not occur soon, more animals will fall ill and die due to plastic consumption from their environment.

Plastic mitigation requires attention from several different fields of study. This issue can be thought about through several different lenses: economics, ecology (the study of organisms and their relationship to their physical environment), microbiology (the study of living organisms too small to be visible with the naked eye), macrobiology (the study of large living organisms), marine biology, and organic chemistry. Each of these disciplines investigates how plastics directly affect what is of interest to them. For example, biologists are interested in how plastic or biodegradable products impact the environment and organisms; those in economics concern themselves with how communities are monetarily impacted by plastics and recycling in general (Eriksen et al., 2018). Why after years of research is plastic waste mitigation still such a large issue? The answer depends on the field. Recycling can be expensive for businesses and communities from a financial perspective. Individuals are only monetarily incentivized to recycle certain items like soda cans and some bottles, but overall, it is cheaper and more convenient to throw away recyclables, which is highly problematic (Eriksen et al., 2018). Another important issue to address is cost: how do we make recycling both easier for the average person, and also cheaper for the communities to participate in? Another recycling-related question that often arises is the science behind biodegradable plastics and biodegradable products because no system is perfect. The average person believes that biodegradable products are better because they degrade "naturally," but most of the time that is simply not the case. Most products that state they are "biodegradable" still require processing in a specific facility that unnaturally heats them to a high temperature to degrade them - this does not solve the problem because, like recycling, 
they are simply not ending up in the facility necessary to break them down properly and are instead being put in landfills (Thompson, 2018).

Recent efforts have begun to analyze the idea of using heterotrophic microbes and their enzymes as a reliable mechanism for plastic degradation. Initially, synthetic polymers such as PET were thought to be resistant to microbial degradation, but recent research has shown that certain microbes can produce hydrolase enzymes that break down or modify the plastic (Carr et al., 2020). The most well-studied plastic-eating microbe is the Eubacteria Ideonella sakaiensis, which utilizes PET plastic as a carbon and energy source (Carr et al., 2020). This means that the microbe I. sakaiensis has the ability to degrade and consume PET, by catalyzing the oxidation-reduction reaction to break down the chemical bonds in the plastic polymers. Deterioration of PET by microbes relies on several physical factors of the plastic, such as surface area, functional groups present, molecular weight, hydrophilic/hydrophobicity, melting temperature, chemical structure, and crystallinity, among others (Jaiswal et al., 2020). Polyesters for example are less likely to degrade because they have side chains (less assimilated than those without side chains). Molecular weight is an important factor, because the higher the molecular weight of a polymer the slower the degradation potential (Jaiswal et al., 2020). Genetic and protein engineering tools have been used to increase microorganisms' ability to degrade plastic, such as modifying the protein's amino acid sequence to increase enzymatic activity and to tolerate reaction conditions (Carr et al., 2020). While this is a scientific breakthrough for the better of our environment, it may be futile if the broken-down plastic, or the organisms performing the degradation release harmful chemicals into the environment (Carr et al., 2020).

Overall, we can see the potential for heterotrophic microbes to serve as a greener approach to recycling certain plastics that may otherwise be put into landfills, burned, or washed 
into rivers and oceans. Through microbial intervention, we can see the life cycle that plastic would take from production, to discard, to breakdown. One of the major attributes to using microorganisms to degrade plastic is the lack of additional external chemicals required to perform the job. Microorganisms are a greener approach that overall costs less energy, is more environmentally friendly, and can target specific plastics that are mixed in with other forms of waste (Cornwall, 2021). From here, we will introduce the bacteria responsible for plastic degradation currently, and address their effectiveness in this role.

\section{Section 1: The Role of Heterotrophic Microbes in Plastic Degradation}

Recycling is not a new concept, however utilizing microbes and their enzymes to degrade plastic is. The most well understood organism identified to be capable of plastic degradation is the heterotrophic bacteria Ideonella sakaiensis. This bacterium was discovered by Japanese scientists in 2016, within a consortium of microorganisms found in a sediment sample taken near a bottle recycling plant in Japan (Flashman, 2018). Researchers were initially unclear on what its mode of energy production was, but genetic analysis determined it was most closely related to Ideonella dechloratans - a chlorate-respiring heterotrophic bacterium (Tanasupawat et al., 2016). Along with the discovery of the bacterium itself was a novel enzyme it produces called PETase. Upon closer observation, researchers realized that the plastic bottles at the facility served as a nutrient source for the bacterium: I. sakaiensis, it uses the hydrolase enzyme PETase to convert PET to mono terephthalate-degrading (MHET), where MHETase finishes breaking down the monomers, however, $\mathrm{CO}_{2}$ is its oxidation byproduct (Carr et al., 2020). I. sakaiensis was then put to the test to determine how its PETase compared to other known PET hydrolyzing enzymes and 
determined that the combination of PETase and MHETase enables I. sakaiensis to degrade plastic at a faster rate than any previously discovered enzymes (Tanasupawat, et al., 2016). The ability for I. sakaiensis to utilize carbon sources for energy rather than creating its own from the sun defines it as a heterotrophic microbe. In this case it appears that PETase allows I. sakaiensis to utilize plastic as a source of energy, which suggests that PETase could be a potential solution in mitigating plastic waste. There is one problem with this process, however. While I. sakaiensis is a naturally occurring bacterium, those harnessed for this study were taken to a bioreactor where they are modified for optimum use, rather than studied in their purely natural form (Flashman, 2018). For example, I. sakaiensis optimally grows at a $\mathrm{pH}$ of 7.0-7.5 and a temperature of $30-37^{\circ} \mathrm{C}$, however it can successfully grow outside of those ranges - in the bioreactor, cultures were growing at $30^{\circ} \mathrm{C}$ (Flashman, 2018; Tanasupawat, et al. 2016). These naturally occurring species have evolved to withstand hardy plastics in the wild and use them as a substrate for energy, but what happens when these modified versions of the natural bacteria make their way into the wild? If bacteria begin eating plastic in the wild rather than in a biological facility, then the product packaging designed to last could potentially come under threat. The plastic/packaging industry would feel forced to prevent their plastics from being contaminated with hungry plastic-eating microorganisms, thus rendering this potential solution to our recycling problem useless because they will create a plastic that is resistant to such bacterial contamination (Flashman, 2018).

Ideonella sakaiensis is not the only bacterium that possesses PET hydrolases - other organisms with similar hydrolases including Thermobifida fusca, Bacillus subtilis, and species from the genera Thermomonospora (Danso et al., 2019).The original function of Thermobifida fusca (formerly belonging to the genus Thermomonaspora) was to degrade the cellulose that 
makes up plant cell walls (Wilson, 2004). This bacterium can be found in decaying organic matter and is a major contributor to degrading plant cell walls (Wilson, 2004). Polyesterase (promoting the degradation of polyesters) was first reported for $T$. fusca by a German research group (Kawai et al., 2019). While this is a function that the organisms still serve, they also contain cutinases (the category to which all PET hydrolases fall under) which degrade the cutin of the cuticular layer in leaves or suberin in bark (Kawai et al., 2019).

Bacillus subtilis is the best studied Gram-positive bacterium, serving as a model organism to study chromosome replication and cell differentiation (Errington and Aart, 2020). Like other Bacillus species, it can form endospores to survive during extreme environmental conditions of temperature and desiccation (Madigan and Martinko, 2006). B. subtilis is unique because it is particularly susceptible to genetic manipulation, which explains its model organism status (Errington and Aart, 2020). B. subtilis has the ability to breakdown PET using PETase, however it does not possess MHETase so it can only break down the larger polymers and not the monomers like I. sakaiensis can with its version of PETase (Danso et al., 2020). While $I$. sakaiensis is more effective by breaking down the monomers, it is more sensitive to extreme temperatures and $\mathrm{pH}$ changes than $B$. subtilis is, thus demonstrating an important trade-off in this research (Danso et al., 2020).

Microbes in the genus Thermomonospora, have contributed to new antibiotics, enzymes, and products capable of pharmacological activity (Chertkov et al., 2011). Like Thermobifida fusca, Thermomonospora species participate in active degradation of cellulose, and this is logical because T. fusca and Thermomonospora spp. are related (Chertkov et al., 2011; Wei et al., 2014). Thermomonospora curvata, for example, is a thermophilic bacterium that produces extracellular hydrolases that degrade synthetic polyesters (Wei et al., 2014). In onestudy, researchers cloned 
and expressed T. curvata genes Tcur1278 and Tcur0390 into the E. coli genome - what is unique about these two specific genes is that they share a $61 \%$ sequence identity with the $T$. fusca enzymes (Wei et al., 2014). The experiment demonstrated that Tcur0390 showed an increased hydrolytic activity against PET nanoparticles when compared to Tcur1278 at 50 degrees celsius. At both 55 and 60 degrees celsius, hydrolytic activity against PET nanoparticles was only present with Tcur1278 (Wei et al., 2014). This confirms the idea that thermal stability in Tcur1278 is the main contributor for higher hydrolytic activity (Wei et al., 2014).

Among the bacteria discussed, Ideonella sakaiensis is the only known organism that contains the MHETase enzyme, which breaks down the monomers of PET after its degradation by PETase, making it the best-suited organism for the job (Danso et al., 2019). Furthermore, unlike I. sakaiensis, PET degradation is not the primary role for any of the other bacteria discussed here, nor for their enzymes. I. sakaiensis has been studied more than other organisms for plastic degradation because it possesses the MHETase enzyme that the others lack, however it is by no means a perfect organism. The largest flaw with using I. sakaiensis and its PETase enzyme is the fact that it is sensitive to changes in temperature and $\mathrm{pH}$, while others are less-so (Danso et al., 2020). Future research could pursue a path in which we find a way to combine strong attributes of several organisms to survive harsh conditions for degradation, without making them so strong that we cannot control them.

While many studies are focused on the impact one microbial species can have on degrading plastic, scientists at Reed College in Portland, Oregon currently are performing groundbreaking research to study the impact of using multiple species of bacteria to break down PET. This research project started with Morgan Vague, a 2018 graduate from Reed, who was interested in researching the relationship between bacteria and plastic for her thesis work under 
Professor Jay Mellies (Lydgate, 2021). The work of Mellies, Vague, and other students on the project is unique because they are investigating soil samples composed of five different strains of bacteria, including Pseudomonas and Bacillus, that are hypothesized to work synergistically to consume PET and convert it into an energy source (Lydgate, 2021). These organisms working synergistically means that they are interacting or cooperating to produce a combined effect that is greater than the sum of their separate effects. Vague wanted to test the bacteria's ability to feed on hydrocarbons, thus she attempted to culture bacteria on shards of plastic. Most of the organisms died, however some did in fact survive - since PET was their only source of nutrition, Vague deducted that they had to be digesting the plastic (Lydgate, 2021). PET is a polymer with long tough strands that are tangled up together, which contributes to its durability but also renders it resistant to biological reactions; however the microbes studied also produce hydrolases that are responsible for the degradation of PET (Lydgate, 2021). Hydrolases are the enzymes that bacteria use to digest food, in this case PET, by chopping long, complex molecules down to a size in which the organisms can absorb or consume them. Plastic is far tougher to digest than any other food source bacteria are likely to be exposed to naturally, however they are adaptable (Lydgate, 2021). The research team spent several months culturing the organisms on PET, and after eight weeks they determined that the PET in one sample had lost three percent of its mass due to bacterial digestion (Lydgate, 2021). Furthermore, this sample contained five different strains of bacteria in which some strains broke down the PET into pieces that other strains could digest, proving yet again that these organisms are synergistic. Now that they have determined that their samples can in fact degrade plastic, the team is now focused on determining ways to make the process more efficient (Lydgate, 2021). 


\section{Section 2: Are plastic-eating microbes an effective solution to the plastic pollution problem?}

As discussed in Section 1, some species of heterotrophic microbes, such as Ideonella sakaiensis can ultimately break down polyethylene plastics, making them potentially effective at mitigating the plastic waste crisis (Danso et al., 2020). While limited work has attempted to study the feasibility of larger-scale processing of plastic waste by microbes, there is still plenty of room for research to be conducted on how effective this solution is for the crisis (Lydgate, 2021). The research conducted by Mellies on plastic-degrading bacteria is not the only success story (Lydgate, 2021). Another team of researchers cultured a consortium of organisms (bacteria, yeast-like cells, and protozoa) on PET film to investigate the microorganisms capable of relying on PET nutritionally (Yoshida et al., 2016). They successfully isolated I. sakaiensis from the consortium, which demonstrated its capability to assimilate PET within the group (Yoshida et al., 2016). Upon observation, the researchers noticed that the PET film was damaged significantly and was almost completely degraded after six weeks at $30^{\circ} \mathrm{C}$ (Yoshida et al., 2016). Shortly after this determination, the researchers performed a subculture analysis where they discovered a sub-consortium that had lost the ability to degrade PET, however this was due to a lack of $I$. sakaiensis in the sample (Yoshida et al., 2016). This indicates that I. sakaiensis is the major functional contributor to degrading PET, and is successful at degrading PET film in as little as six weeks, when compared to nature where the breakdown process could take upwards of 50 to several hundred years depending on the conditions (Yoshida et al., 2016). This is a significant breakthrough in terms of the time in which it takes to break down plastics, however there are concerns for commercializing this technique due to drawbacks from the breakdown process (Taniguchi et al., 2019). 
The PETase enzyme found in Ideonella sakaiensis demonstrates the highest PET hydrolytic activity when compared to the PETase enzymes from other bacteria, like Thermobifida fusca for example (Taniguchi et al., 2019). While this would typically be a positive attribute to this bacteria and its respective enzyme, this characteristic is only true at mild temperatures, because the enzyme is heat-labile, or able to be destroyed or altered by heat (Taniguchi et al., 2019). Researchers find the heat-labile characteristic of the I. sakaiensis PETase to be rather unusual when compared to the thermophilic bacteria's PETase enzymes because their PET Hydrolytic Enzymes (PHEs) are biochemically characteristic of their thermophilic hosts, making the enzyme more thermostable but less hydrolytically active than the I. sakaiensis version (Taniguchi et al., 2019).

One of the largest downfalls of using bacteria and their enzymes as a prominent technique to combat plastic waste is that the PETase can only target the one specific type of plastic - PET. Unfortunately, several different types of plastics accumulate in marine and terrestrial environments that often contain solubilizers and other chemical additives used to alter the plastic's properties to make them stronger and more resistant to degradation (Carr et al., 2020; Danso et al., 2019). While it is not concrete, researchers are concerned that the added solubilizers may interfere with the enzyme's degradation activities (Carr et al., 2020; Danso et al., 2019). One concept that researchers are in agreement with is the low turnover rates of PET hydrolase enzymes (PHEs), especially when interacting with highly crystallized forms of PET plastic (Carr et al., 2020; Danso et al., 2019; Taniguchi et al., 2019). The turnover rate of an enzyme is the maximum number of molecules of substrate that are converted to product when the enzyme is saturated with substrate, so in this case PHEs have a low maximum number of 
PET molecules that they convert to the products terephthalate (TPA) and ethylene glycol (EG) (Roskowski, 2007; Tanigushi et al., 2019).

Previously, issues related more to chemical drawbacks have been discussed, however it is worth noting some of the environmental drawbacks that could come from releasing such bacteria into the natural environment. Releasing plastic-eating microorganisms into the environment is a potential problem for manufacturers because they want to protect their plastic food and drink packaging from microbial contamination as much as possible (Thompson, 2018). If the organisms are not contained in a facility for their work, manufacturers would be forced to make their already problematic single-use packaging resistant to microbial degradation - thus completely undermining the process of using microorganisms in the first place (Thompson, 2018).

Another significant environmental drawback stems from the release of $\mathrm{CO}_{2}$, a known greenhouse gas, as a waste product of the plastic consumption process (Thompson, 2018) This is problematic because excessive levels of $\mathrm{CO}_{2}$ cause the "greenhouse effect," where excess gasses released into the atmosphere create a "dome" that traps the sun's heat energy, resulting in the warming of the planet/oceans, and significant changes in weather patterns (Buis, 2021). The only potential solution to solve this problem is to either find an organism to harvest the $\mathrm{CO}_{2}$ for another purpose or contain the bacteria in a facility where they can control what happens to the $\mathrm{CO}_{2}$ byproduct (Thompson, 2018). If one were to pursue finding an organism to harvest carbon dioxide for another purpose, methanogens would be a natural group to start with. However, methanogens are methane-producing bacteria that reduce carbon dioxide into methane, unfortunately producing another powerful greenhouse gas that may only contribute further to the problem. While $\mathrm{CO}_{2}$ production by microbes is a major drawback, it is still a step in the right 
direction in terms of solving our problem. It is important to acknowledge that we should not release genetically modified bacteria into the environment without fully understanding potential consequences such as gene transfer. Horizontal gene transfer is a realistic consequence upon release into the natural environment because bacteria naturally share genes as they respond and adapt to their environment rapidly by acquiring DNA sequences from another bacterium (Keeling \& Palmer, 2008). Horizontal gene transfer in this case could result in at least a couple of scenarios: 1) Ideonella sakaiensis, for example, could acquire new genes in the natural environment that could affect what it feeds on and how it responds in the environment, and 2) Other microorganisms that could not previously breakdown plastic may acquire the genetic material to do so - this could be good or bad. The important point to remember is that the use of recombinant organisms for environmental application differs greatly from a contained laboratory environment. Given the potential drawbacks from using I. sakaiensis for plastic degradation, researchers still have unknowns to address, especially regarding the greenhouse effect. This work must be conducted before we should consider microbes as a viable solution to plastic mitigation, however the work that has been conducted regarding microbes is certainly a step in the right direction.

\section{Conclusion:}

We know that plastic waste is problematic for marine and terrestrial ecosystems due to the mass production and poor disposal of polyethylene terephthalate (PET) plastics for food containers, films, fibers, and bottles. The primary aim of this thesis was to explore the potential utility of plastic-eating microbes for plastic degradation, rather than conventional methods for disposal (burning, landfilling) and recycling. In understanding this aim, I investigated two 
primary questions: 1) What role can microbes play in plastic degradation? and 2) Are plastic eating microbes an effective solution to the plastic pollution problem? Through a literature review, I investigated how microbes used plastic as an energy source to determine if they were a viable solution to shield our ecosystems from the rise of plastic pollution. Overall, I discovered that, on the scale necessary to solve the global problem of plastic pollution, relying primarily on these plastic-eating microbes is currently unrealistic. The work of Milles has demonstrated success, however success in the lab does not yet correlate to success in real world applications (Lydgate, 2021). The research behind the Ideonella sakaiensis model is groundbreaking, and will likely lead to further research into mitigation of the plastic waste crisis using heterotrophic microbes. Future research could likely continue to focus on expanding small-scale experiments on heterotrophic microbes to larger scale processing in an industrial waste facility (Carr et al., 2020), or working to combine the high PETase hydrolytic activity with thermostable PHEs to incorporate higher thermostability to PETase (Taniguchi et al., 2019).

Unfortunately, Earth has experienced a continuous and growing problem with plastic waste since the 1950s, when plastic production skyrocketed. An important question we should all be asking is "Why after all these years, is plastic waste still a persistent problem?" Obviously, the best way to mitigate our plastic problem is to stop producing new plastic and relying on plastic altogether, however this is simply unrealistic. Even if plastic production were halted today, we must still address the plastic pollution present on Earth. Recycling is a critical step, and to-date, more well established than microbial heterotrophs to help mitigate waste (e.g. Eriksen et al. 2018). However, recycling relies on two factors: 1) citizens recycling their plastics and 2) plastic waste ending up in specific facilities where they can be properly processed. 
Incentivisation has been promising when used but it is not used nationwide. Container deposit fees incentivize returning containers in exchange for a small monetary incentive in states California, Hawaii, Oregon, Connecticut, Delaware, Maine, Vermont, Massachusetts, Iowa, Michigan, and New York. With that in mind, it is no surprise then that Maine, Vermont, Massachusetts, Oregon, Connecticut, New York, Michigan, and Iowa are among New Jersey and Minnesota for the ten states with the highest recycling rates. This method has been more effective than curbside bin recycling because consumers are paid (Eriksen et al, 2018). Fees and taxing on plastic bags have encouraged customers to bring their own reusable bags to avoid the fee, which theoretically reduces plastic consumption, but this is less favorable than monetary incentivization because individuals would rather be paid to participate in recycling than charged to avoid using plastic (Eriksen et al., 2018).

More research obviously must be conducted to establish how viable long-term reuse could be in practice, however at this time we know that the integrity of plastic decreases with each turn at recycling. If PET does manage to be captured for recycling, it is typically downcycled to a cheaper, lower quality, non-recyclable plastic where it becomes an even greater problem to the environment.. Another form of recycling plastic could be to chemically break them apart into other molecules that could be used for other purposes, such as fuels or pharmaceuticals, however once again this requires more research on how feasible this is as a solution as our ability to break down plastics into "safe" compounds is questionable (Thompson, 2018).

Even if halting the production of new plastics entirely is unrealistic, there are steps that can be taken to lower our plastic demand, and thus carbon footprints, such as shopping more frequently at local farmers markets (little to no packaging); avoid single-use plastics as best we 
can (drinking straws, plates, cutlery); using reusable bags made from cloth, string, or wicker; buy in bulk; replace plastic tupperware with glass containers; reuse some of that packaging that you do have to purchase rather than throwing it out immediately after its single use; and avoid using cosmetics that contain microplastics. These are just a few simple ways that we as the consumer can take matters into our own hands regarding our use of single-use plastics. We should also let our wallets speak for themselves by simply not purchasing the types of products that require such packaging if we can help it. This will drive down the demand for them, and may cause companies to reconsider their approach. While it may feel like there is nothing we can do to overcome our monumental amount of plastic waste, that is simply not the case. We can start by making small changes in our daily lives and hold these large, plastic-producing companies accountable for the waste that they are generating in our environment. 


\section{References}

Ariza-Tarazona, Maria Camila, et al. "New Strategy for Microplastic Degradation: Green Photocatalysis Using a Protein-Based Porous N-TiO2 Semiconductor.” Ceramics International, vol. 45, no. 7, May 2019, pp. 9618-9624. Part B, doi:https://doi.org/10.1016/j.ceramint.2018.10.208.

Buis, Alan. "The Atmosphere: Getting a Handle on Carbon Dioxide - Climate Change: Vital Signs of the Planet." NASA, NASA, 3 Mar. 2020, climate.nasa.gov/news/2915/the-atmosphere-getting-a-handle-on-carbon-dioxide/.

Carr CM, Clarke DJ, Dobson ADW. Microbial Polyethylene Terephthalate Hydrolases: Current and Future Perspectives. Front Microbiol. 2020 Nov 11;11:571265. Doi:

10.3389/fmicb.2020.571265. PMID: 33262744; PMCID: PMC7686037

Chertkov, Olga, et al. "Complete Genome Sequence of Thermomonospora Curvata Type Strain (B9T)." Standards in Genomic Sciences, vol. 4, no. 1, 20 Feb. 2011, pp. 13-22., https://doi.org/10.4056/sigs. 1453580.

Cornwall, Warren. "Could Plastic-Eating Microbes Take a Bite out of the Recycling Problem?" Waste Advantage Magazine, 5 July 2021, https://wasteadvantagemag.com/could-plastic-eating-microbes-take-a-bite-out-of-the-rec ycling-problem/.

Danso, Dominik, Jennifer Chow, Wolfgang R. Streit. "Plastics: Environmental and Biotechnological Perspectives on Microbial Degradation." Applied and Environmental Microbiology, vol. 85, no. 19, 17 Sept. 2019, https://doi.org/10.1128/aem.01095-19. 
De Lorenzo, Víctor. “Cleaning up behind Us.” EMBO Reports, vol. 2, no. 5, 15 May 2001, pp. 357-359., https://doi.org/10.1093/embo-reports/kve100. Accessed 26 Oct. 2021.

Doyle, M. J., Watson, W., Bowlin, N. M., \& Sheavly, S. B. (2011). Plastic particles in coastal pelagic ecosystems of the Northeast Pacific Ocean. Marine Environmental Research, 41-52.

Eriksen, Marcus, et al. Freshwater Microplastics: Emerging Environmental Contaminants?, by Martin Wagner and Scott Lambert, Springer International Publishing, 2018, pp. 273-298, link.springer.com/chapter/10.1007/978-3-319-61615-5_13

Errington, Jeffery, and Lizah T Aart. "Microbe Profile: Bacillus Subtilis: Model Organism for Cellular Development, and Industrial Workhorse.” Microbiology, vol. 166, no. 5, 11 May 2020, pp. 425-427., https://doi.org/10.1099/mic.0.000922.

Flashman, Emily. "How Plastic-Eating Bacteria Actually Work - a Chemist Explains." The Conversation, 18 Apr. 2018, theconversation.com/how-plastic-eating-bacteria-actually-work-a-chemist-explains-95233.

Furukawa, M., Kawakami, N., Tomizawa, A., \& Miyamoto, K. (2019). Efficient degradation of poly(ethylene terephthalate) with thermobifida fusca cutinase exhibiting improved catalytic activity generated using mutagenesis and additive-based approaches. Scientific Reports, 9(1). https://doi.org/10.1038/s41598-019-52379-z

Huerta Lwanga, E., Gertsen, H., Gooren, H., Peters, P., Salánki, T., van der Ploeg, M., Besseling, E., Koelmans, A. A., \& Geissen, V. (2016). Microplastics in the terrestrial ecosystem: 
Implications for lumbricus terrestris (Oligochaeta, Lumbricidae). Environmental Science \& Technology, 50(5), 2685-2691. https://doi.org/10.1021/acs.est.5b05478

Gleizer, Shmuel, et al. "Conversion of Escherichia Coli to Generate All Biomass Carbon from CO2." Cell, vol. 179, no. 6, 27 Nov. 2019, pp. 1255-1263., doi:https://doi.org/10.1016/j.cell.2019.11.009.

Jaiswal, Shweta, et al. "Integrated Approaches in Microbial Degradation of Plastics." Environmental Technology \&amp; Innovation, vol. 17, Feb. 2020, doi:https://doi.org/10.1016/i.eti.2019.100567.

Kawai, Fusako, et al. "Current Knowledge on Enzymatic PET Degradation and Its Possible Application to Waste Stream Management and Other Fields." Applied Microbiology and Biotechnology, vol. 103, no. 11, 8 Apr. 2019, pp. 4253-4268., https://doi.org/10.1007/s00253-019-09717-y.

Keeling, P. J., \& Palmer, J. D. (2008). Horizontal gene transfer in eukaryotic evolution. Nature Reviews Genetics, 9(8), 605-618. https://doi.org/10.1038/nrg2386

Isangedighi, I. A., David, G. S., \& Obot, O. I. (2021). Plastic Waste in the Aquatic Environment. In Analysis of nanoplastics and microplastics in food (1st ed., pp. 55-84). essay, CRC Press, Taylor \& Francis Group.

Lahive, E., Walton, A., Horton, A. A., Spurgeon, D. J., \& Svendsen, C. (2019). Microplastic particles reduce reproduction in the terrestrial worm enchytraeus crypticus in a soil exposure. Environmental Pollution, 255, 113174.

https://doi.org/10.1016/i.envpol.2019.113174 
Llorca, Marta, and Marinella Farré. "Current Insights into Potential Effects of Micro-Nanoplastics on Human Health by in-Vitro Tests." Frontiers in Toxicology, vol. 3, 29 Sept. 2021, https://doi.org/10.3389/ftox.2021.752140.

Lydgate, Chris. “These Microbes Eat Water Bottles.” Reed Magazine, 18 Mar. 2021, https://www.reed.edu/reed-magazine/articles/2021/reed-biologists-plastic-eating-bacteria. $\underline{\mathrm{html}}$

Madigan, Michael T., and J. M. Martinko. Brock Biology of Microorganisms. 11th Ed. 11th ed., Prentice-Hall, 2006.

Markic, A., Gaertner, J.-C., Gaertner-Mazouni, N., \& Koelmans, A. A. (2019). Plastic ingestion by marine fish in the wild. Critical Reviews in Environmental Science and Technology, 50(7), 657-697. https://doi.org/10.1080/10643389.2019.1631990

Nelms, S.E., Barnett, J., Brownlow, A. et al. Microplastics in marine mammals stranded around the British coast: ubiquitous but transitory? Sci Rep 9, 1075 (2019). https://doi.org/10.1038/s41598-018-37428-3

Orlando, Alex. "Scientists Just Created a Bacteria That Eats CO2 to Reduce Greenhouse Gases." Discover Magazine, Discover Magazine, 27 Nov. 2019, $\underline{\text { www.discovermagazine.com/environment/scientists-just-created-a-bacteria-that-eats-co2-to }}$ -reduce-greenhouse-gases.

Postgate, John Raymond. Microbes and Man. Cambridge University Press, 2003. 
Ritchie, Hannah, and Max Roser. "Plastic Pollution.” Our World in Data, 1 Sept. 2018, ourworldindata.org/plastic-pollution.

Roberts, Cameron, et al. "Environmental Consortium Containing Pseudomonas and Bacillus Species Synergistically Degrades Polyethylene Terephthalate Plastic.” MSphere, vol. 5, no. 6, 23 Dec. 2020, https://doi.org/10.1128/msphere.01151-20.

Roskoski, R. (2007). Michaelis-Menten Kinetics. XPharm: The Comprehensive Pharmacology Reference, 1-10. https://doi.org/10.1016/b978-008055232-3.60041-8

Sharuddin, Shafferina Dayana Anuar, et al. Energy Conversion and Management, vol. 115, May 2016, pp. 308-326., https://doi.org/https://doi.org/10.1016/j.enconman.2016.02.037.

Tahir, Muhammad Bilal, et al. Nanotechnology and Photocatalysis for Environmental Applications, ELSEVIER, 2020, pp. 57-64.

Tanasupawat, Somboon, et al. "Ideonella Sakaiensis Sp. Nov., Isolated from a Microbial Consortium That Degrades Poly(Ethylene Terephthalate).” International Journal of Systematic and Evolutionary Microbiology, vol. 66, no. 8, 2016, pp. 2813-2818., https://doi.org/10.1099/ijsem.0.001058.

Taniguchi, I., Yoshida, S., Hiraga, K., Miyamoto, K., Kimura, Y., \& Oda, K. (2019). Biodegradation of PET: Current status and application aspects. ACS Catalysis, 9(5), 4089-4105. https://doi.org/10.1021/acscatal.8b05171

Thompson, Andrea. “Solving Microplastic Pollution Means Reducing, Recycling-and Fundamental Rethinking.” Scientific American, Scientific American, 12 Nov. 2018, 
$\underline{\text { www.scientificamerican.com/article/solving-microplastic-pollution-means-reducing-recy }}$ cling-mdash-and-fundamental-rethinking1/.

Wei, Ren, et al. "Functional Characterization and Structural Modeling of Synthetic Polyester-Degrading Hydrolases from Thermomonospora Curvata." AMB Express, vol. 4, no. 1, 3 June 2014, https://doi.org/10.1186/s13568-014-0044-9.

Wilkes, R. A., and L. Aristilde. "Degradation and Metabolism of Synthetic Plastics and Associated Products by Pseudomonas Sp.: Capabilities and Challenges." Journal of Applied Microbiology, vol. 123, no. 3, 17 Apr. 2017, doi:https://doi.org/10.1111/jam.13472.

Wilson, David B. "Studies Of Thermobifida Fusca Plant Cell Wall Degrading Enzymes." The Chemical Record, vol. 4, no. 2, 1 Apr. 2004, pp. 72-82., https://doi.org/10.1002/tcr.20002.

Yoshida, S., Hiraga, K., Takehana, T., Taniguchi, I., Yamaji, H., Maeda, Y., Toyohara, K., Miyamoto, K., Kimura, Y., \& Oda, K. (2016). A bacterium that degrades and assimilates poly(ethylene terephthalate). Science, 351(6278), 1196-1199.

https://doi.org/10.1126/science.aad6359 